\title{
Reactivity Sites in Dopamine Depend on its Intramolecular Hydrogen Bond
}

\author{
Erwin García-Hernández ${ }^{1 *}$ and Jorge Garza ${ }^{2}$
}

1 Departamento de Posgrado e Investigación, División de Mecatrónica, Instituto Tecnológico Superior de Zacapoaxtla, Carretera Acuaco-Zacapoaxtla Kilómetro 8, Totoltepec, C.P. 73680. Zacapoaxtla Puebla, México.

2 Departamento de Química, División de Ciencias Básicas e Ingenierías. Universidad Autónoma Metropolitana-Iztapalapa. San Rafael Atlixco 186, Col. Vicentina, Iztapalapa. C.P. 09340. México D.F., México.

* erwin.garcia@live.itsz.edu.mx

Received October 28 ${ }^{\text {th }}, 2016$; Accepted March $28^{\text {th }}, 2017$.

\begin{abstract}
In this work, three conformers of dopamine were theoretically analyzed, two of them forming an intramolecular hydrogen bond between $\mathrm{OH}$ groups in the catechol moiety, the third one without this interaction. The used theoretical method was based on the Kohn-Sham method within the hybrid exchange-correlation functionals without empirical parameters, PBE0. The molecular geometry obtained by this method was contrasted with that obtained from the second-order many-body perturbation theory (MP2) method and the $6-31+\mathrm{G}(\mathrm{d})$, $6-311+\mathrm{G}(\mathrm{d})$ and $6-311++\mathrm{G}(\mathrm{d}, \mathrm{p})$ basis sets. Global reactivity descriptors were predicted by using only the PBE0/6-311++G(d,p) method. This method revealed that dopamine is not a good acceptor of electrons. Thus, in one charge transfer process, this compound prefers donating electrons, as observed experimentally. All global chemical predictors do not show important changes regardless of the presence of an intramolecular hydrogen bond. However, in the case of local reactivity predictors, oxygen atoms of the catechol moiety exhibit changes when this contact is present. This conclusion was confirmed when 8 catechol derivatives were analyzed with the same procedure applied over the dopamine. Additionally, the carbon atoms opposite to the carbon atoms linked to oxygen atoms, in the catechol moiety, present the biggest changes when these systems donate one electron. Consequently, the electron involved during the charge transfer process of these systems will be detached from the region defined between these two carbon atoms.
\end{abstract}

Keywords: Dopamine; Catechol's derivatives; Conceptual DFT.

\section{Introduction}

Dopamine (DA) is a neurotransmitter produced in the human body in a natural way. This compound plays an important role in the regulation of hormonal secretion in the central nervous system and organs involved in the control of motor, cognition and neuroendocrine functions. Furthermore, this is present in regions of the brain that regulate movement and emotion. [1] An improper regulation of this neurotransmitter is associated with neurological diseases such as Parkinsonism, where dopamine levels are reduced, or schizophrenia, where a high activity of dopamine has been registered. [2 - 4] By its structure, DA can be a precursor in the synthesis of other catecholamines in the human body, like epinephrine and norepinephrine. [5] There is evidence that catecholamines neurotransmitters, like dopamine, show antioxidant activity and consequently reactive
Resumen. En este trabajo, fueron estudiadas teóricamente tres conformaciones de la dopamina, dos de ellas formando un puente de hidrógeno intramolecular entre los grupos $\mathrm{OH}$ de la fracción catecol y la tercera sin esta interacción. La geometría molecular obtenida con PBE0 fue contrastada con la generada usando el método MP2 y las funciones de base $6-31+\mathrm{G}(\mathrm{d}), 6-311+\mathrm{G}(\mathrm{d})$ y $6-311++\mathrm{G}(\mathrm{d}, \mathrm{p})$. Para predecir los índices globales de reactividad, se utilizó la metodología PBE0/6-311++G(d,p). Éste reveló que la dopamina no es un buen aceptador de electrones. Así, en un proceso de transferencia de carga este compuesto prefiere donar electrones como ha sido observado experimentalmente. Todos los índices globales de reactividad no presentan cambios cuando el puente de hidrógeno intramolecular está o no está presente. En cambio, para índices locales de reactividad, claramente los átomos de oxígeno de la fracción catecol exhiben cambios cuando se forma el enlace de hidrógeno intramolecular. Esta conclusión fue confirmada analizando 8 derivados del catecol con el mismo procedimiento aplicado a la dopamina. Además, los átomos de carbono opuestos a los carbonos unidos a los oxígenos en el catecol, presentan grandes cambios cuando estos sistemas donan un electrón. Así, el electrón involucrado durante el proceso de transferencia de carga de estos sistemas, será removido de la región definida entre estos dos átomos de carbono.

Palabras clave: Dopamina; Derivados de catecol; DFT Conceptual.

oxygen species (ROS) react with these compounds under oxidative stress conditions, [6 - 14] inducing neuroprotective effects. Structurally, DA is formed by a catechol fraction and one aliphatic chain with a terminal amino group (Fig. 1). The catechol moiety in this compound is considered as a powerful antioxidant. $[15,16]$

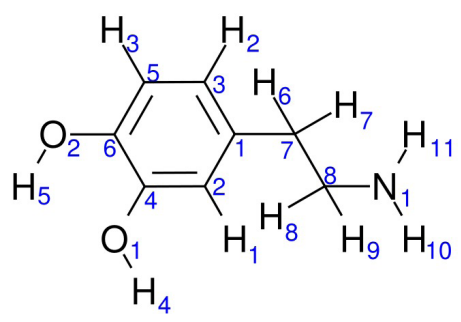

Fig. 1. Dopamine. 
By the side of theoretical studies, there is one report where a computational kinetic study is carried out on the reactivity of dopamine toward hydroxyl $(\bullet \mathrm{OH})$ and hydroperoxyl $(\bullet \mathrm{OOH})$ free radicals, in aqueous and lipidic simulated biological environments. The main interest of this study is the evaluation of its free radical scavenging capacity. In such a work, the authors propose a mechanism of the reaction as a sequential electron proton transfer and hydrogen atom transfer. For the first step, the electron detachment is carried out in the catechol moiety, hence the importance of this group in the properties of dopamine. Finally, they conclude that DA is a very good $\bullet \mathrm{OOH}$, and presumably $\bullet \mathrm{OOR}$, radical scavenger. [17] In addition of this work, Lu and Yu estimated theoretically the ionization potential, on different conformations, of the dopamine. The study deals with two molecular geometries. One, where an intramolecular hydrogen bond (IHB) is present on the - $\mathrm{OH}$ in catechol moiety, and the another one, where the $-\mathrm{OH}$ groups are in one opposite direction, and consequently the contact $\mathrm{O}-\mathrm{H} \cdots \mathrm{O}$ is not present. Thus, the involved IHB lies in the definition by the IUPAC about a hydrogen bond, where donor and acceptor are two atoms with high electronegativity.[18]

They conclude that the conformers with the IHB are more stable, nevertheless, the ionization potential of both conformers does not differ appreciably. [19] On this direction, several theoretical investigations have been reported about the formation of the IHB, and its role, on systems with catecholic rings. In particular, Ortega-Moo et al., have characterized this contact over some substituted catechols, by using three scalar fields, the non-covalent interaction index, the electron density through the atoms in molecules theory and the electron localization function. From their results, none of the scalar fields used ensures that an IHB is present in these kind of compounds, [20] giving important information about this possible contact. In addition, Ortega-Moo et al. show that this contact is totally irrelevant to describe several chemical reactivity indicators.

In our knowledge, one study related to chemical reactivity indicators for dopamine is still missing. It is well known that within the density functional theory (DFT) framework, there are several indicators that are useful to predict the most reactive sites in a molecule. [21,22] For this reason, in this short report, several chemical reactivity indicators defined within the DFT framework are used to study the dopamine. The aim of this study is to predict the sites where the dopamine donates electrons and how these sites are modified if an intramolecular hydrogen bond is present or not.

\section{Theory}

In DFT, two groups of reactivity indices allow the study of any chemical system; global and local. [21,22] On the side of global predictors, the chemical potential $(\mu)$ [23] and the hardness (ๆ) [24] are defined as

$$
\mu=\left(\frac{\partial E}{\partial N}\right)_{v(r)}
$$

$$
\eta=\left(\frac{\partial^{2} E}{\partial N^{2}}\right)_{v(r)}
$$

where $E$ and $N$ represent the total energy and the number of electrons of the system, respectively. From these definitions, clearly the external potential, $v(\mathbf{r})$, is fixed. For molecular systems, this restriction means that all nuclei keep their positions when the system accepts or gives electrons. By using a finite difference approximation, $\mu$ and $\eta$ can be evaluated as

$$
\begin{aligned}
& \mu \approx-\frac{I+A}{2}, \\
& \eta \approx I-A,
\end{aligned}
$$

where $I$ is the ionization potential and $A$ the electronic affinity. Another global reactivity index, defined by Parr et. al. is the electrophilicity written as [25]

$$
\omega=\frac{\mu^{2}}{2 \eta}
$$

This quantity determines the susceptibility in one molecule to accept electrons. For the evaluation of these quantities, the discontinuity in the derivatives has been recognized from initial stages of the DFT. For that reason, Gázquez, Cedillo and Vela, proposed the electroaccepting $\left(\omega^{+}\right)$and electrodonating $\left(\omega^{-}\right)$ powers, [26,27] associated with the acceptance and donation of charge in a molecular system. These quantities are defined as

$$
\begin{aligned}
& \omega^{+}=\frac{\left(\mu^{+}\right)^{2}}{2 \eta}, \\
& \omega^{-}=\frac{\left(\mu^{-}\right)^{2}}{2 \eta},
\end{aligned}
$$

where $\mu^{+}$and $\mu^{-}$are defined by

$$
\begin{aligned}
& \mu^{+}=-\frac{1}{4}(I+3 A), \\
& \mu^{-}=-\frac{1}{4}(3 I+A) .
\end{aligned}
$$

Within the finite difference approximation, these quantities are obtained from

$$
\begin{aligned}
& \omega^{-} \approx \frac{(3 I+A)^{2}}{16(I-A)}, \\
& \omega^{+} \approx \frac{(I+3 A)^{2}}{16(I-A)} .
\end{aligned}
$$


On the side of local reactivity, Parr and Yang proposed the Fukui function [28]

$$
f(r)=\left(\frac{\partial \rho(r)}{\partial N}\right)_{v(r)}
$$

as one quantity to identify regions of the system where the density responses when the number of electrons is modified. Thus, $f^{-}$predicts sites where the system is susceptible of one electrophilic attack,

$$
f^{-}(r)=\left(\frac{\partial \rho(r)}{\partial N}\right)_{v(r)}^{-}=\rho_{N_{0}}(r)-\rho_{N_{0}-1}(r)
$$

while $f^{+}$predicts sites where nucleophilic attacks are expected, through the expression

$$
f^{+}(r)=\left(\frac{\partial \rho(r)}{\partial N}\right)_{v(r)}^{+}=\rho_{N_{0}+1}(r)-\rho_{N_{0}}(r)
$$

In addition, it is quite useful the definition of regional values for these local quantities. Sometimes, regional or condensed Fukui functions are obtained from

$$
\begin{aligned}
& f_{i}^{-}=q_{i}(N-1)-q_{i}(N), \\
& f_{i}^{+}=q_{i}(N)-q_{i}(N+1) .
\end{aligned}
$$

In these equations, $q_{i}$ represents an atomic charge, defined by $q_{i} \equiv Z_{i}-Q_{i}$, where $Z_{i}$ is the atomic number and $Q_{i}$ the electronic charge on $i$ th atom, which is estimated by using a population analysis like those obtained from Mulliken, [29] Merz-Singh-Kollman [30,31] or Hirshfeld, [32] at the $i$ th atomic site. Connecting Fukui functions and electro-donor or -acceptor powers, the local electroaccepting $\left[\omega^{+}(\mathrm{r})\right]$ and electrodonating $\left[\omega^{-}(\mathrm{r})\right]$ powers are defined as

$$
\begin{aligned}
& \omega^{+}(r)=\omega^{+} f^{+}(r), \\
& \omega^{-}(r)=\omega^{-} f^{-}(r) .
\end{aligned}
$$

Naturally, their corresponding condensed quantities are obtained from eqs. 15 and 16.

\section{Computational details}

All calculations were done with the NWChem v6.3 suite code. [33] For this study, three conformations of the dopamine were considered, two of them forming an intramolecular hydrogen bond (IHB) between $\mathrm{OH}$ groups in catechol moiety. Thus, from Fig. 1, one IHB $\left(\mathrm{DA}_{1}\right)$ is formed between $\mathrm{O} 1$ and $\mathrm{H} 5$ and a second IHB $\left(\mathrm{DA}_{2}\right)$ is formed between $\mathrm{O} 2$ and $\mathrm{H} 4$. An additional confomer $\left(\mathrm{DA}_{\mathrm{wo}}\right)$ was considered, where no IHB is present. Geometry optimizations and frequency analysis were carried out by using the PBE0 exchange-correlation functional.[34] In addition, the second-order many-body perturbation theory, MP2, [35] was considered just for the geometrical analysis. For all methods, 6-31+G(d), 6-311+G(d) and 6-311+ $+\mathrm{G}(\mathrm{d}, \mathrm{p})$ basis sets were used to see basis set effects on geometrical parameters. [36] In order to test one hypothesis proposed in this work, eight additional compounds were considered, with and without IHB. These compounds are based on the catechol moiety, which correspond to those studied by Ortega et al.[20], these structures are represented in Fig. 2. By the side of reactivity descriptors, the systems were analyzed by using the PBE0/6-311 $++\mathrm{G}(\mathrm{d}, \mathrm{p})$ method.

The electron affinity was estimated from

$$
A=E_{(N)}-E_{(N+1)}
$$

and the ionization potential from

$$
I=E_{(N-1)}-E_{(N)}
$$

Global predictors as hardness $(\eta),[24]$ chemical potential $(\mu),[23]$ electrodonating $\left(\omega^{-}\right)$and electroaccepting $\left(\omega^{+}\right)$powers $[26,27]$ were evaluated by using $I$ and $A$ estimated from eqs. 19 and 20 . In order to obtain information about the reactivity sites in dopamine, the Fukui functions and condensed values of local predictors were necessary. In this work, the partial atomic charges that fit the molecular electrostatic potential were used to calculate the condensed Fukui functions and from here local electrodonating and electroaccepting powers. [26,27]

\section{Results and discussion}

\subsection{Geometry analysis}

The dopamine conformers considered in this work are presented in Fig. 3. For this compound, the MP2/6-311++G(d,p) method predicts $\mathrm{DA}_{1}$ and $\mathrm{DA}_{2}$ more stable than $\mathrm{DA}_{\text {wo }}$ by $4.6 \mathrm{kcal} /$ mol respect to $\mathrm{DA}_{1}$ and $4.1 \mathrm{kcal} / \mathrm{mol}$ respect to $\mathrm{DA}_{2}$, while the PBE0/6-311++G(d,p) shows a difference of $4.2 \mathrm{kcal} / \mathrm{mol}$ and $4.4 \mathrm{kcal} / \mathrm{mol}$, respectively. For the catechol, this energy difference is of $4.1 \mathrm{kcal} / \mathrm{mol}$ [37] and for systems related with catechol also exhibit an energy difference of $4.1 \mathrm{kcal} / \mathrm{mol}$. [20]

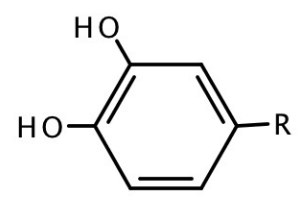

Fig. 2. Structures obtained from Ortega et al. [20] with $\mathrm{R}=\mathrm{H}, \mathrm{CH}_{3}$, $\mathrm{CH}_{2} \mathrm{CH}_{3}, \quad\left(\mathrm{CH}_{2}\right)_{2} \mathrm{CH}_{3}, \mathrm{CH}=\mathrm{CH}_{2}, \mathrm{CH}=\mathrm{CHCOOH}, \mathrm{CO}\left(\mathrm{CH}_{2}\right)_{4} \mathrm{CH}_{3}$, $\mathrm{COOH}$. 
Table 1. Some structural parameters for three conformers of dopamine, $\mathrm{DA}_{1} / \mathrm{DA}_{2} / \mathrm{DA}_{\mathrm{wo}}$

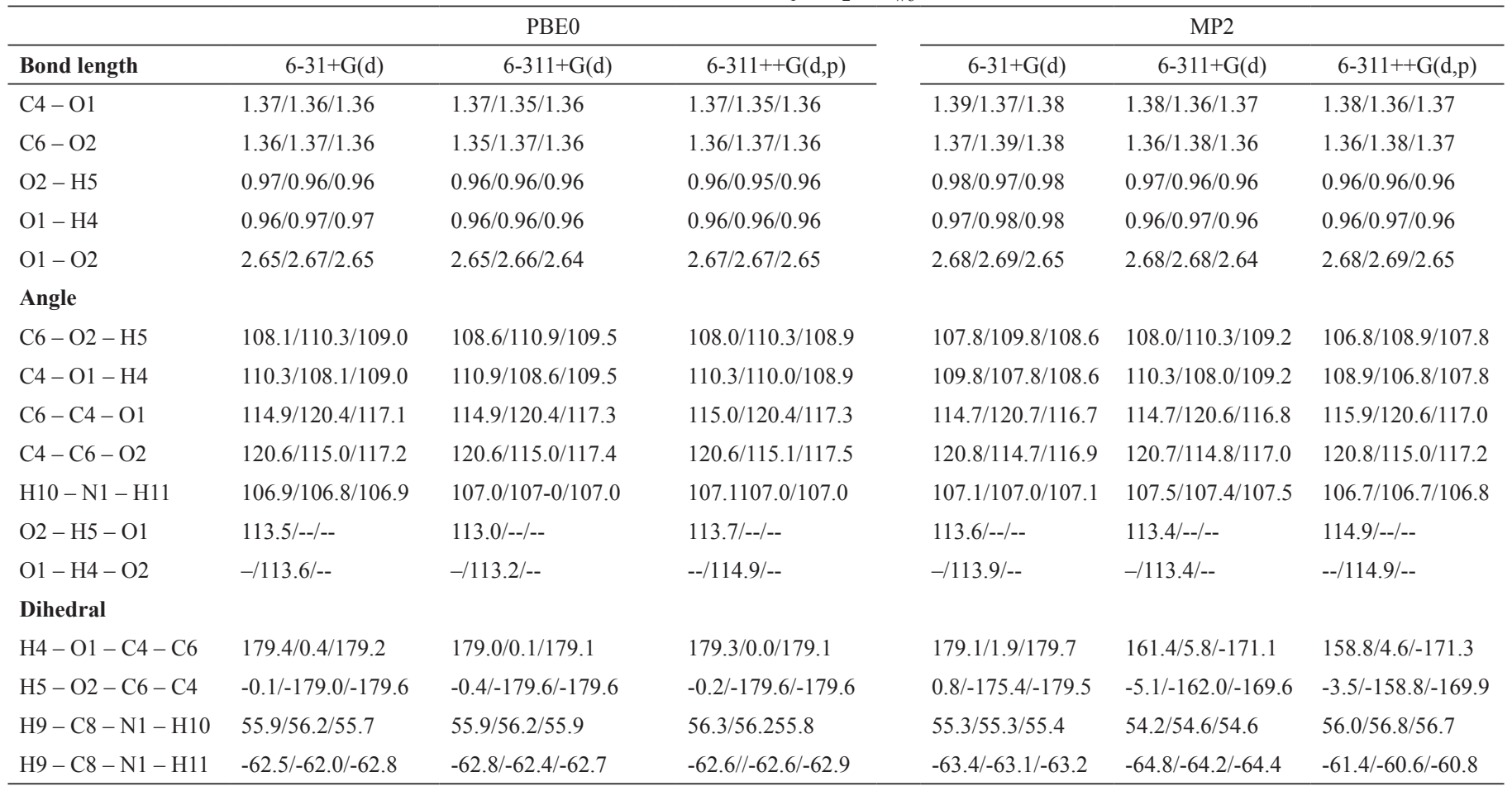

Thus, estimations given in this work, deliver similar information to results reported in other studies. Some geometrical parameters obtained for $\mathrm{DA}_{1}, \mathrm{DA}_{2}$ and $\mathrm{DA}_{\text {wo }}$ are reported in Table 1.

By using the MP2/6-311++G(d,p) method as reference, it is clear that one additional diffuse function and one additional polarization function have important impact on MP2 calculations but not for PBE0, since for PBE0 the differences are almost zero between $6-311+G(d)$ and $6-311++G(d, p)$ basis sets. In fact, we can say that even the small basis set $6-31+\mathrm{G}(\mathrm{d})$ gives similar results than those obtained by the biggest one. We must recognize that the difference found between PBE0 and MP2 with the largest basis set are rather small. Thus, we can conclude that for dopamine the PBE0 exchange-correlation functional works well to predict its geometrical structure. The same conclusion is reached when the D3 Grimme dispersion approximation [38] is applied over the same systems. For that reason, we use only the PBE0 exchange-correlation functional.

\subsection{Global reactivity descriptors}

Ionization potential and electron affinity are the first quantities to be analyzed within the global predictors group for $\mathrm{DA}_{1}, \mathrm{DA}_{2}$ and $\mathrm{DA}_{\mathrm{wo}}$. These quantities are reported in Table 2. It is worth to note, that $A$ is negative for all conformers explored in this work. This is an important conclusion, because it means that dopamine is not good acceptor of charge. On the other hand, the ionization potential is reported in the same table. There are reports where this quantity has been evaluated for several conformers of dopamine. [19] Comparing $I$ with results obtained by $\mathrm{Lu}$ and $\mathrm{Yu}$, these authors report 7.74 and $7.73 \mathrm{eV}$ by using B3LYP/6-311++G(d,p) and B3PW91/6-311++G(d,p), respectively. For our case, the PBE0/6-311++G(d,p) predicts $I=7.80$ $\mathrm{eV}$ for $\mathrm{DA}_{1}$, which is close to those values reported by $\mathrm{Lu}$ and $\mathrm{Yu}$, while for $\mathrm{DA}_{2}$, they report an ionization potential of 7.71 $\mathrm{eV}$ for both methods, in this work the estimation to this

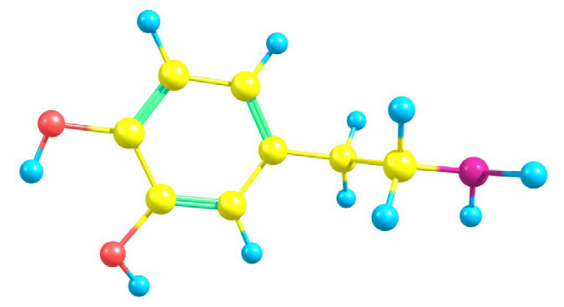

(a) $\mathrm{DA}_{1}$

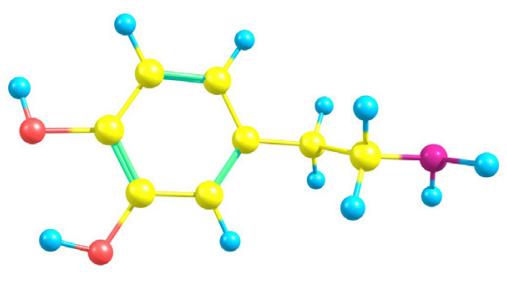

(b) $\mathrm{DA}_{2}$

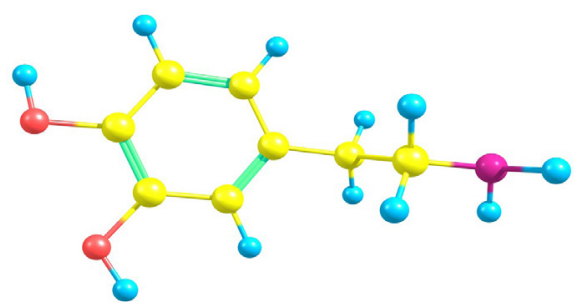

(c) $\mathrm{DA}_{\text {wo }}$

Fig. 3. Conformers of dopamine optimized with MP2/6-311++G(d,p) method. 
Table 2. Global reactivity descriptors for the three conformers of Dopamine obtained by the PBE0 exchange-correlation functional and $6-311++\mathrm{G}(\mathrm{d}, \mathrm{p})$ basis function.

\begin{tabular}{cccc}
\hline Property & $\mathrm{DA}_{1}$ & $\mathrm{DA}_{2}$ & $\mathrm{DA}_{\text {wo }}$ \\
\hline $\mathrm{I}$ & 7.80 & 7.82 & 7.75 \\
$\mathrm{~A}$ & -0.31 & -0.38 & -0.40 \\
$-\mu^{-}$ & 5.77 & 5.77 & 5.71 \\
$-\mu^{+}$ & 1.72 & 1.67 & 1.63 \\
$\eta$ & 4.06 & 4.1 & 4.07 \\
$\omega^{-}$ & 4.11 & 4.06 & 3.99 \\
$\omega^{+}$ & 0.36 & 0.34 & 0.33 \\
\hline
\end{tabular}

All the values are in a.u., except $I$ and $A$, they are in $\mathrm{eV}$.

property is $7.82 \mathrm{eV}$. For $\mathrm{DA}_{\mathrm{wo}}$, the prediction from PBE0/6$311++\mathrm{G}(\mathrm{d}, \mathrm{p})$ is $I=7.75 \mathrm{eV}$, which is slightly lower than that predicted for $\mathrm{DA}_{1}$. This behavior is also observed by $\mathrm{Lu}$ and $\mathrm{Yu}$ since they report for this quantity 7.67 and $7.66 \mathrm{eV}$, when B3LYP/6-311++G(d,p) and B3PW91/6-311++G(d,p) are applied on $\mathrm{DA}_{\mathrm{wo}}$, respectively.

It is known that the ionization potential is associated to the antioxidant capacity for this kind of compounds, since this quantity is directly related to one of the mechanism that drives the oxidation process; the electron transfer. Thus, from Table 2 we can see that all conformers exhibit almost the same value for this property, i. e. the IHB has no impact on $I$. This result agrees with results reported by Ortega-Moo et al., where it is remarkable that this IHB is not relevant for the antioxidant capacity in a family of catechols and resorcinols. [20] Global chemical predictors revised in Section 2 are reported in Table 2 for $\mathrm{DA}_{1}$, $\mathrm{DA}_{2}$ and $\mathrm{DA}_{\mathrm{wo}}$. From this table, it is evident that $\omega^{+}$exhibits small values, since the electron affinity has an important weight on this quantity and therefore the dopamine is not good electron acceptor, as it was mentioned above. By comparing these quantities for the three conformers, $\mathrm{DA}_{\text {wo }}$ present the smaller value for $\omega^{-}$and $\omega^{+}$, while for $\eta$ practically there are no differences. For $\omega^{-}$the relative difference (in percent) between $\mathrm{DA}_{1}, \mathrm{DA}_{2}$ and $\mathrm{DA}_{\mathrm{wo}}$ goes from $1.0 \%$ to $3.0 \%$ respect to $\mathrm{DA}_{1}$. For $\mu^{-}$, the changes are smaller than those observed for $\omega^{-}$and they are observed when the IHB is not present. Thus, $\mu^{-}, \eta$ and $\omega^{-}$ change in a marginal way when the IHB is present or not. Thus, the IHB has a small role over the global chemical predictors involved in a charge process where the dopamine is involved.

\subsection{Local reactivity descriptors}

In last section, it was shown that global chemical predictors for processes where dopamine gives charge, do not change appreciably when the IHB is considered or not. In this section, some local reactivity predictors are explored to see if the same conclusion is valid locally. For this goal, Fukui functions are the quantities to be explored. In this work, $f^{-}(\mathbf{r})$ and $f^{+}(\mathbf{r})$ have been evaluated as a difference between electron densities, according to eqs. 13 and 14 . For a process where the dopamine donates charge, the corresponding $f^{-}(\mathbf{r})$ is presented in Fig. 4 for $\mathrm{DA}_{1}, \mathrm{DA}_{2}$ and $\mathrm{DA}_{\mathrm{wo}}$. From a visual analysis, it is not possible distinguish differences among the conformers, since for all cases the biggest response of this quantity is found over the atoms O1, O2, C1, C3, C4, C6 and N1. Also for the three conformers, the $f^{-}$has important contributions over the bonds defined by the atoms $\mathrm{C} 4-\mathrm{C} 6$ and $\mathrm{C} 1-\mathrm{C} 3$. This is an interesting result since $\mathrm{OH}$ groups have an important impact on the atoms where they are binded, however, the delocalization involved within the ring induces important changes on $\mathrm{C} 1$ and $\mathrm{C} 3$ atoms and over the $\mathrm{C} 1-\mathrm{C} 3$ bond.

At this point, a visual analysis has been discussed around $\mathrm{DA}_{1}, \mathrm{DA}_{2}$ and $\mathrm{DA}_{\mathrm{wo}}$ conformers, although a quantitative analysis is necessary to give conclusions. For this reason, a population analysis is needed, which is presented in Table 3, where the condensed local electro-donating and - accepting powers are reported for atoms that exhibit $\omega_{c}>0.1$. In principle, large values of this quantity indicate sites where the system prefers to donate or accept electrons, in our case we will focus the discussion on $\omega_{c}^{-}$. For $\mathrm{DA}_{1}$, it is evident that $\mathrm{C} 1, \mathrm{~N} 1, \mathrm{O} 2$ and $\mathrm{C} 3$ are the four atoms with the biggest value of $\omega_{c}^{-}$and for $\mathrm{DA}_{2}$, the atoms with the biggest response are $\mathrm{C}_{1}, \mathrm{~N}_{1}, \mathrm{O}_{1}$ and $\mathrm{C}_{3}$. This observation gives one important conclusion, oxygen atoms acting as acceptors $\left(\mathrm{O}_{\mathrm{A}}\right)$ to form a hydrogen bond reduce their response to give electrons. This result has sense since these atoms provide electrons to form a hydrogen bond. In addition, we found that $\omega_{O D}^{-} \approx 2 \omega_{O A}^{-}$, where $\mathrm{O}_{\mathrm{D}}$ represents an oxygen atom acting as donor in a hydrogen bond.

From Table 3 and Fig. 4, there is an interesting result. We mentioned above, from Fig. 4, that $\omega^{-}(\mathbf{r})$ is localized between

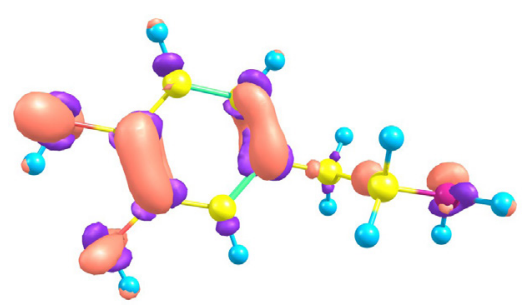

(a)

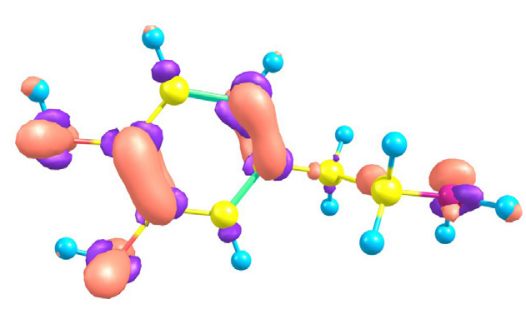

(b)

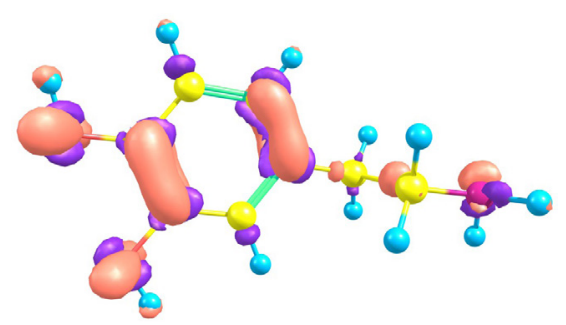

(c)

Fig. 4. Fukui function $\left(f^{-}\right)$for (a) $\mathrm{DA}_{1}$, (b) $\mathrm{DA}_{2}$ and (c) $\mathrm{DA}_{\mathrm{wo}}$ 
Table 3. Electrodonating and electroaccepting powers for $\mathrm{DA}_{1}, \mathrm{DA}_{2}$ and $\mathrm{DA}_{\mathrm{wo}}$ by using PBE0/6-311++G(d,p). All values are in a.u.

\begin{tabular}{ccccccc}
\hline & \multicolumn{3}{c}{$\omega_{c}^{-}$} & & & $\omega_{c}^{+}$ \\
\hline Atom & $\mathrm{DA}_{1}$ & $\mathrm{DA}_{2}$ & $\mathrm{DA}_{\text {wo }}$ & $\mathrm{DA}_{1}$ & $\mathrm{DA}_{2}$ & $\mathrm{DA}_{\text {wo }}$ \\
\hline $\mathrm{C} 1$ & 0.7 & 0.5 & 0.6 & 0.2 & 0.1 & 0.1 \\
$\mathrm{~N} 1$ & 0.7 & 0.8 & 0.6 & 0.0 & 0.0 & 0.0 \\
$\mathrm{O} 2$ & 0.6 & 0.4 & 0.4 & 0.0 & 0.0 & 0.0 \\
$\mathrm{C} 3$ & 0.4 & 0.7 & 0.6 & 0.0 & 0.0 & 0.0 \\
$\mathrm{O} 1$ & 0.3 & 0.6 & 0.5 & 0.0 & 0.0 & 0.0 \\
$\mathrm{H} 6$ & 0.3 & 0.3 & 0.3 & 0.1 & 0.1 & 0.1 \\
$\mathrm{H} 7$ & 0.3 & 0.3 & 0.3 & 0.1 & 0.1 & 0.1 \\
$\mathrm{C} 4$ & 0.3 & 0.2 & 0.3 & 0.0 & 0.0 & 0.0 \\
$\mathrm{C} 6$ & 0.3 & 0.3 & 0.3 & 0.0 & -0.1 & 0.0 \\
$\mathrm{H} 9$ & 0.3 & 0.3 & 0.2 & 0.1 & 0.1 & 0.1 \\
$\mathrm{H} 4$ & 0.2 & 0.1 & 0.2 & 0.2 & 0.0 & 0.1 \\
$\mathrm{H} 8$ & 0.2 & 0.0 & 0.2 & 0.1 & 0.1 & 0.1 \\
$\mathrm{H} 1$ & 0.1 & 0.1 & 0.1 & 0.1 & 0.0 & 0.1 \\
$\mathrm{H} 3$ & 0.1 & 0.1 & 0.1 & 0.0 & 0.1 & 0.1 \\
\hline & 0.1 & 0.1 & 0.2 & 0.0 & 0.2 & 0.1 \\
\hline
\end{tabular}

$\mathrm{C} 1$ and $\mathrm{C} 3$ (including both atoms). We will assume that the information of $\omega^{-}(\mathbf{r})$ along the $\mathrm{C} 1-\mathrm{C} 3$ bond is contained in the condensed information of $\mathrm{C} 1$ and $\mathrm{C} 3$. Therefore, we propose that for bound regions where the $\omega^{-}(\mathbf{r})$ is delocalized, the corresponding condensed information is obtained from the sum of the sites that bound such a region. Thus, $\omega_{C 1}^{-}+\omega_{C 3}^{-}=1.1$ for $\mathrm{DA}_{1}$ and 1.2 for $\mathrm{DA}_{2}$, represent the biggest value of the condensed local electroaccepting power. We conclude that the detachment of one electron from the DA will be trough the region defined by the $\mathrm{C} 1-\mathrm{C} 3$ bond. By doing the same analysis on the $\mathrm{DA}_{\mathrm{wo}}$ structure, it is impressive the response obtained for the oxygen atoms. Both atoms acquire almost same values for the condensed $\omega^{-}$, and the region defined by $\mathrm{C} 1$ and $\mathrm{C} 3$ keeps almost the same value (1.2 a.u.). These results are quite important since the IHB observed in the dopamine is not relevant for global quantities, like total energy, ionization potential or $\eta$. However, we are showing that this contact has an important impact on the local electrodonating power. To corroborate this conclusion, eight additional catechol derivatives were tested, such compounds correspond to those reported in Fig. 3 of reference [20] and Fig. 2 of this report, where the substituent is changed on the para position. For this case, the evaluation of $f_{C}^{-}$is enough to validate our conclusions, which is reported in Table 4. From here, there is no a doubt that the reactivity of the oxygen atoms in the catechol moiety is the same when the IHB is not present. Contrary to this behavior, if the IHB is present then these atoms respond in a different way. Additionally, $\mathrm{C} 1$ and $\mathrm{C} 3$ atoms show the biggest values for $f_{C}^{-}$among all atoms in the nine tested systems, and $f_{C 1}^{-}+f_{C 3}^{-}$present the biggest value.

Table 4. Condensed $f^{-}$for dopamine and eight derivatives of the catechol. For this case the substituents are: 1) $\mathrm{H}_{2}$ 2) $\left.\mathrm{CH}_{3}, 3\right) \mathrm{CH}_{2} \mathrm{CH}_{3}$, 4) $\left(\mathrm{CH}_{2}\right)_{2} \mathrm{CH}_{3}$, 5) $\mathrm{CH}=\mathrm{CH}_{2}$, 6) $\left.\left.\mathrm{CH}=\mathrm{CHCOOH}, 7\right) \mathrm{COOH}, 8\right) \mathrm{CO}\left(\mathrm{CH}_{2}\right)_{4} \mathrm{COOH}$. All quantities are in a.u.

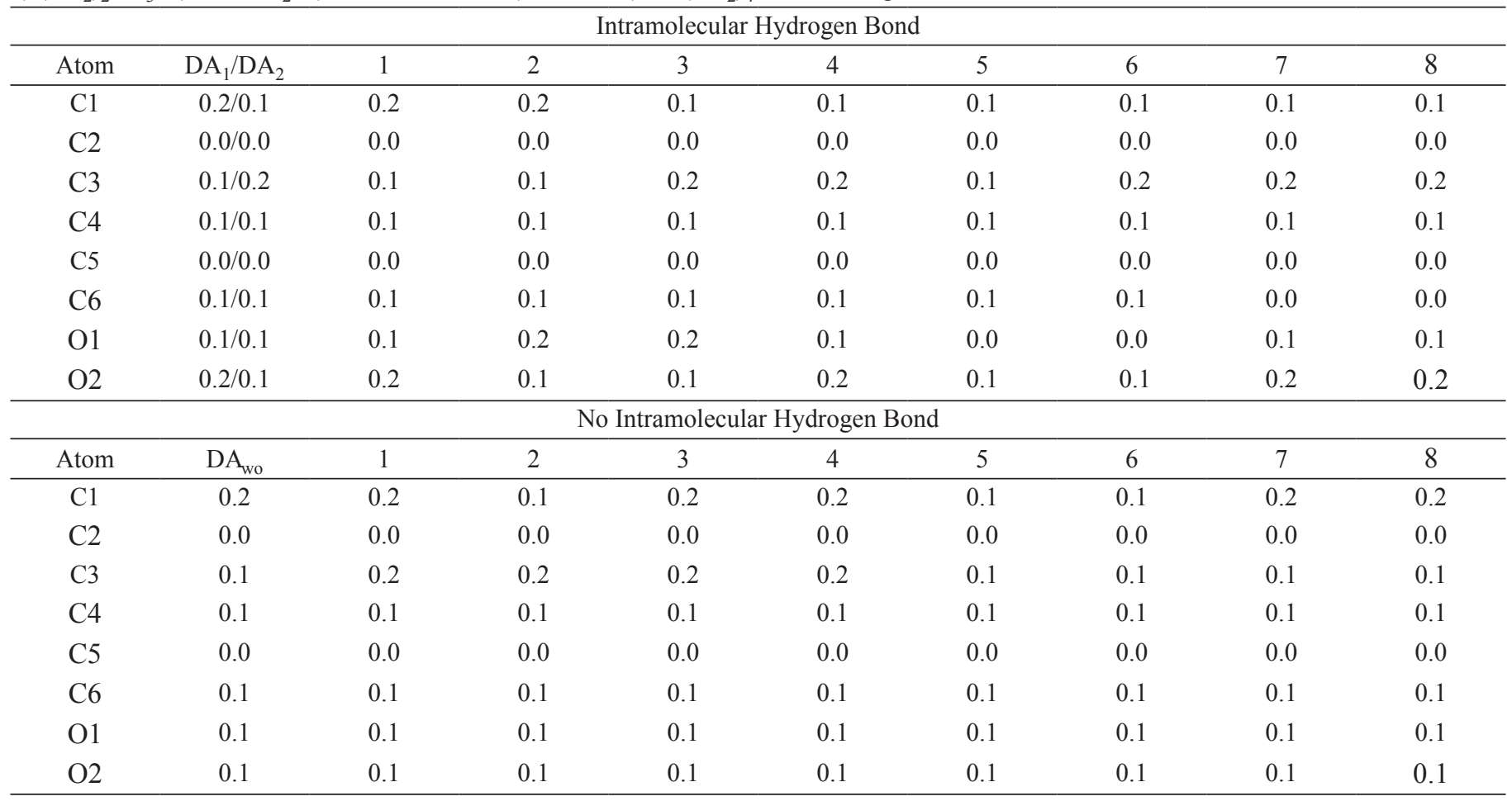




\section{Conclusions}

In this work, three conformations of the dopamine were analyzed by using DFT descriptors, $\omega^{+}(\mathbf{r})$ and $\omega^{-}(\mathbf{r})$. The results suggest that dopamine is not good acceptor of charge. It was possible to observe that when an electrophilic attack occurs, the catechol moiety is the preferred site, especially the region defined by the atoms $\mathrm{C} 1$ and $\mathrm{C} 3$. The most important result found in this short report, is the influence of the intramolecular hydrogen bond over local reactivity descriptors and not over the global counterpart. Such a conclusion was obtained with nine analyzed system, all related with catechol derivatives.

\section{Acknowledge}

Authors thank the Laboratorio de Supercómputo y Visualización en Paralelo at the Universidad Autónoma Metropolitana for access to their computer facilities.

\section{References}

1. Cooper J. R.; Bloom F. E.; Roth R. H., The Biochemical Basis of Neuropharmacology; Oxford University Press, NewYork, 1986.

2. Birkmayer, W.; Riederer, P., Understanding the Neurotransmitters: Key to the Workings of the Brain; Springer-Verlag: New York, 1989.

3. Mathews, C. K.; Van Holde, K. E. Biochemistry; The Benjamin/ Cummings Publishing Company, Inc.: Menlo Park, CA, 1996.

4. Liu J.; Mori A. Arch. Biochem. Biophys. 1993, 302, 118-127.

5. Juárez-Olguín H.; Calderón-Guzmán D.; Hernández-García E.; Barragán-Mejía G. Oxid. Med. Cell. Longev. 2016, $2016,9730467$.

6. Terland O.; Almas B.; Flatmark T.; Andersson K. K.; Sørlie M. Free Radic. Biol. Med. 2006, 41, 1266-1271.

7. Hattoria N.; Wanga M.; Taka H.; Fujimura T.; Yoritaka A.; Kubo S.; Mochizuki H. Parkinsonism Relat. Disord. 2009, 15, S35-S38.

8. Stokes A. H.; Hastings T. G.; Vrana K. E. J. Neurosci. Res. 1999, 55, 659-665.

9. Graham D. G. Mol. Pharmacol. 1978, 14, 633-643.

10. Napolitano A.; Pezzella A.; Prota G. Chem. Res. Toxicol. 1999, 12, 1090-1097.

11. Jiang D.; Shi S.; Zhang L.; Liu L.; Ding B.; Zhao B.; Yagnik G.; Zhou F. ACS Chem. Neurosci. 2013, 4, 1305-1313.

12. Jodko-Piórecka K.; Litwinienko G. Free Radical Biol. Med. 2015, $83,1-11$.
13. Yen G. C.; Hsieh C. L. Biosci. Biotech. Biochem. 1997, 61, 1646-1649.

14. Mohammad-Shiri H.; Ghaemi M.; Riahi S.; A. Akbari-Sehat Int. J. Electrochem. Sci. 2011, 6, 317-336.

15. Cao G.; Sofic E.; Prior L. R. Free Radicals Biol. Med. 1997, 22, 749-760.

16. Kerry N.; Rice-Evans C. J. Neurochem. 1999, 73, 247-253.

17. Iuga C.; Alvarez-Idaboy J. R.; Vivier-Bunge A. J. Phys. Chem. B 2011, 115, 12234-12246.

18. Arunan E.; Desiraju G. R.; Klein R. A.; Sadlej J.; Scheiner S.; Alkorta I.; Clary D. C.; Crabtree R. H.; Dannenberg J. J.; Hobza P.; Kjaergaard H. G.; Legon A. C.; Mennucci B.; Nesbitt D. J. Pure Appl. Chem. 2011, 83, 1637-1641.

19. Lu J. F.; Yu Z. Y. Russian Journal of Physical Chemistry A 2013, 87, 628-633.

20. Ortega-Moo C., Garza J.; Vargas R. Theor. Chem. Acc. 2016, 135, 177-188.

21. Gázquez J. L. J. Mex. Chem. Soc. 2008, 52, 3-10.

22. Geerlings P.; De Proft F.; Langenaeker W. Chem. Rev. 2003, 103, 1793-1874.

23. Parr R. G.; Donnelly R. A.; Levy M.; Palke W. E. J. Chem. Phys. 1978, 68, 3801-3807.

24. Parr R. G.; Pearson R. G. J. Am. Chem. Soc. 1983, 105, 7512-7516.

25. Parr, R. G.; Von Szentpaly, L.; Liu, S. B. J. Am. Chem. Soc. 1999, 121, 1922-1924.

26. Gázquez J. L.; Cedillo A.; Vela A. J. Phys. Chem. A 2007, 111, 1966-1970.

27. Morell C.; Gázquez J. L.; Vela A.; Guegan F; Chermette H. Phys. Chem. Chem. Phys. 2014, 16, 26832-26842.

28. Parr R. G.; Yang W. J. Am. Chem. Soc. 1984, 106, 4049-4050.

29. Mulliken R. S. J. Chem. Phys. 1955, 23, 1833-1840.

30. Singh U. C.; Kollman P. A. J. Comp. Chem. 1984, 5, 129-145.

31. Besler B. H.; Merz Jr. K. M.; Kollman P. A. J. Comp. Chem. 1990, 11, 431-439.

32. Hirshfeld F. Theor. Chim. Acta 1977, 44, 129-138.

33. Valiev M.; Bylaska E. J.; Govind N.; Kowalski K.; Straatsma T. P.; van Dam H. J. J.; Wang D.; Nieplocha J.; Apra E.; Windus T. L.; de Jong W. A. Comput. Phys. Commun. 2010, 181, 1477-1489.

34. Adamo C.; Barone V. J. Chem. Phys. 1999, 110, 6158-6170.

35. Møller C.; Plesset M. S. Phys. Rev. 1934, 46, 618-622.

36. Ditchfield R.; Hehre W. J.; Pople J. A. J. Chem. Phys. 1971, 54, 724-728.

37. Zhang H. Y.; Sung Y. M., Wang X. L. Chem. Eur. J. 2003, 9, 502-508.

38. Grimme S.; Ehrlich S.; Goerigk L. J. Comp. Chem. 2011, 32, 1456-1465. 